\begin{tabular}{lllllllllllllllllllllllllllllllll}
\hline$R$ & $E$ & $V$ & I & S & T & A & D & E & E & S & T & U & D & I & O & S & I & N & T & E & R & N & A & C & I & O & N & $A$ & L & $E$ & S
\end{tabular}

\title{
Unas Naciones Unidas para el siglo XXI
}

Boris Yopo Herrera

Director de Postgrado y Profesor, Instituto de Estudios

Internacionales, Universidad de Chile.

Pocos discuten hoy que la Organización de las Naciones Unidas necesita importantes reformas para adecuarse a los desafíos del nuevo siglo. Por una parte, el número de países que la integran se ha cuadruplicado desde su creación en 1945, llegando a 197 miembros en este año 2005. Pero además, la agenda internacional es hoy mucho más extensa y compleja, mientras que una nueva distribución del poder internacional hace necesario un rediseño que incorpore estos cambios, si se pretende tener efectividad en el manejo de los principales problemas internacionales del siglo XXI.

Hace algunos meses, una comisión de alto nivel integrada por 16 personalidades internacionales entregó, a solicitud del Secretario General, Kofi Annan, una propuesta amplia de reformas orientada a poner al día a la organización, con los cambios y nuevos desafíos existentes en el mundo de hoy. La composición y representatividad de esta comisión (entre otros, participaron los ex Cancilleres de China y Rusia, Qian Qichen y Yevgeny Primakov, y el ex Asesor de Seguridad Nacional de Bush padre, Brent Scowcroft), hicieron que el Secretario General adoptara casi íntegramente las recomendaciones en la propuesta de reformas 
que presentó en marzo pasado ${ }^{1}$.

Como es sabido, buena parte de las críticas a la organización tienen que ver con una estructura creada para un mundo que ya no existe, y con la parálisis que experimentó durante la Guerra Fría, cuando ambas superpotencias utilizaban discrecionalmente el veto ante cualquier resolución que afectaran sus intereses o las de sus socios más cercanos. Esto condujo mucha veces a una irrelevancia de las Naciones Unidas en situaciones de conflicto a nivel internacional y a la creciente burocratización de sus procesos internos, donde la "papelería", el asambleísmo, y los nombramientos discrecionales eran la práctica cotidiana.

Sin embargo, el mundo de hoy es demasiado complejo y peligroso para prescindir de una organización que agrupa y confiere legitimidad a un sistema global que, a diferencia de los países, carece de una autoridad central con poderes coercitivos para imponer el respeto a las normas de convivencia que garantizan la paz y la estabilidad internacionales. Como señaló un editorial reciente del New York Times, sin la organización mundial, no habría control eficaz contra la proliferación nuclear, combate coordinado contra el sida y la pobreza, acciones preventivas contra el genocidio, reconstrucción de "estados fallidos", o manejo colectivo de grandes crisis internacionales (la propia administración Bush ha debido recurrir al Consejo de Seguridad para buscar una salida al embrollo de Irak o en la reconstrucción de Afganistán).

De aquí, entonces, la importancia de las reformas propuestas por el Secretario General, quien al presentar el plan pidió expresamente a los países asumir las propuestas en su conjunto, evitando una adopción selectiva de partes de este, que puede llevar al fracaso de la idea original de abordar de manera simultánea y comprensiva los principales dilemas que enfrenta la organización. Sin embargo, en temas altamente sensibles como la reforma al Consejo de Seguridad, Kofi Annan asumió como válidas las dos opciones presentadas por el panel de expertos: agregar seis miembros permanentes u ocho miembros semi permanentes que representarían a las diversas realidades regionales, dejando la decisión final al debate que tendrá lugar en la próxima Asamblea

\footnotetext{
1 "Annan Urges Reform at the U.N", Internacional Herald Tribune, 21 de marzo, 2005.
} 
General de septiembre de 2005.

Existe consenso en que el manejo colectivo de conflictos internacionales, en el futuro, requiere de una nueva representatividad en el Consejo de Seguridad, que dé cuenta de la actual distribución de poder internacional, en particular, el surgimiento de nuevas potencias regionales que tienen una gravitación cada vez mayor en el manejo y la resolución de conflictos locales. Sin embargo, las propias rivalidades regionales dificultan transformar el consenso en torno a la idea de ampliación, en una fórmula aceptable para los principales actores involucrados. Así, por ejemplo, en Asia, China se opone a la incorporación de Japón, debido a las rivalidades históricas, pero también por las múltiples fricciones actuales (sobre Taiwán, islas en el mar de China, alianza de Japón con Estados Unidos, etc.), y además por la proyección de poder futuro de ambas potencias en el Continente Asiático. En Europa, Italia se ha opuesto permanentemente al reconocimiento de Alemania como nuevo representante Europeo, y lo mismo sucede en América Latina respecto de Brasil, donde Argentina y México han hecho saber públicamente sus desacuerdos al respecto. En Africa, por otra parte, el mejor derecho que algunos otorgan a Sudáfrica, es contestado por Egipto y por Nigeria.

Algunos han advertido, además, que entre los criterios de selección deben contar no solo el PGB, tamaño geográfico o equilibrios regionales, sino también, la disposición que han demostrado los países interesados hasta ahora en asumir responsabilidades internacionales y apoyar la resolución multilateral de los principales problemas en la actual agenda mundial ${ }^{2}$. Pero si este es el debate entre los posibles aspirantes, también existe una crítica hacia los actuales miembros permanentes y el uso que han hecho del veto al interior del Consejo de Seguridad. Los fundadores de las Naciones Unidas siempre concibieron el uso del veto en relación con materias que afectaban directamente la paz y seguridad internacional. Sin embargo, con el tiempo y en el contexto de la Guerra Fría, se fue produciendo una "desnaturalización" en su uso, y los cinco permanentes han usado este derecho en materias que no guardan relación con la idea original que inspiro su creación. En los próximos debates en la asamblea general, esto será

2 Ver editorial del New York Times, “A U.N for the $21^{\text {st }}$ Century”, 7 de diciembre de 2005 . 
con seguridad objeto de controversia, sobre todo si estos países pretenden mantener el monopolio del veto en cualquier reforma que se haga en el próximo tiempo.

Un paso importante en la reforma propuesta por el Secretario General, en un tema altamente sensible después de los eventos del 11 de septiembre, es una nueva definición (por primera vez) compartida de lo que constituye "terrorismo", entendido ahora genéricamente como cualquier ataque con fines políticos a "grupos civiles desarmados, no combatientes". Esto terminaría con el uso político intencionado que se le ha dado históricamente al término, donde grupos, individuos y países eran calificados de "terroristas" o "luchadores por la libertad" dependiendo del espectro ideológico en que se encontraba el que calificaba una acción. Un consenso en torno a la definición debiese facilitar decisiones colectivas en el futuro, orientadas a castigar y aislar en aquellos casos donde sea evidente que el accionar de un actor tiene por objetivo afectar primariamente a civiles desarmados e inocentes.

Además del terrorismo, el informe identifica las otras cinco amenazas interconectadas, a la paz y seguridad internacional: persistencia de conflictos interestatales, guerras civiles, amenazas a la estabilidad económico-social, proliferación de armas de destrucción masiva y crimen internacional organizado. En tal sentido, hay un reconocimiento importante hoy, respecto de que ningún país, por poderoso que sea, puede resolver problemas en alguna de estas áreas sin la cooperación de otros Estados también involucrados en estas materias. La mayor interdependencia global hace también más vulnerable a todos, tarde o temprano, y solo con políticas cooperativas de largo plazo será posible abordar con efectividad estas nuevas amenazas no convencionales a la seguridad.

Un tema que ha surgido con fuerza en los últimos años, considerando los ataques sorpresivos en algunos conflictos regionales, es el reconocimiento del derecho a la "defensa anticipatoria" en caso de amenaza inminente. Esto último, sin embargo, no implica para nada legitimar la noción de "guerra preventiva". La comisión de expertos que asesoró al Secretario General fue taxativa en no innovar respecto del artículo 51, que restringe el uso de la fuerza a casos de autodefensa frente a un ataque, recomendando que en caso de una acción de "defensa anticipatoria", esta debería ampararse en el capítulo 7, a través de un mandato específico del 
Consejo de Seguridad. Pero además establece cinco parámetros, llamados "criterios de legitimidad", para el uso de la fuerza: la gravedad de la amenaza, claridad de propósitos, uso de medios proporcionales a la amenaza, apelar a esta como "último recurso", y un balance (estimación) de las consecuencias de hacer uso de la fuerza militar. Así, se busca conciliar la necesidad de acción temprana, pero evitando dar herramientas legales a países que por su capacidad militar tienden a preferir las acciones "unilaterales" a nivel internacional.

Igualmente, el informe Annan ratifica la legitimidad de intervenciones humanitarias para proteger a poblaciones indefensas, en casos de genocidio y graves violaciones a los derechos humanos. Amparado en el concepto de la "responsabilidad de proteger", adoptado del informe Evans del $2001^{3}$, el documento señala que es obligación de la comunidad internacional intervenir cuando la protección de los derechos ciudadanos básicos es violentada masivamente, como resultado de la acción u omisión de un Estado. Existiendo ya una oficina de "alerta temprana" en la sede de Nueva York, y con la incorporación de este nuevo principio, debiese ser posible una acción más eficaz del organismo en situaciones de crisis humanitarias.

Sin embargo, el interés y la voluntad política de las grandes potencias, y de los países con gravitación regional, sigue siendo crucial para materializar acciones colectivas que protejan a poblaciones indefensas en conflictos étnicos. Después de las matanzas en Ruanda y Burundi, el resultado ha sido mixto; en Haití por ejemplo, hay una operación que con todas las dificultades ha logrado sin embargo impedir una guerra civil y estabilizar la situación, pero en la zona de Darfur, en Sudán, hay múltiples informes de atrocidades sin que se haya hecho nada efectivo hasta ahora. Tal vez estos dos ejemplos indican la creciente importancia de involucrar a actores regionales en la pacificación de conflictos locales, especialmente en casos donde las grandes potencias son reticentes a una participación directa.

El informe Annan incluye, además, dos proposiciones interesantes para reforzar las acciones de pacificación a nivel global. Constatando que el $50 \%$ de los países que emergen de graves

3 Gareth Evans, Mohamed Sahnoun (editores), The Responsibility to Protect, IDRC, Canada, diciembre, 2001.

4 "Special Report on the United Nations", The Economist, 20 de noviembre 
conflictos vuelve a reincidir en un período de cinco años, el Secretario General propone crear una comisión de "construcción de la paz" (peacebuilding comission), y también un fondo para la promoción de la democracia, que permita aportar, entre otros, asesoría técnica y apoyo legal a países con democracias frágiles. Con esto, se busca evitar que en situaciones de inestabilidad se llegue a lo que en la literatura internacional de los últimos años se ha llamado "estados fallidos", cuya recuperación es mucho más compleja y costosa que si se actúa de manera anticipatoria frente a una potencial crisis.

En el ámbito de la asistencia humanitaria, el Secretario General ha vuelto a insistir en la necesidad de que los países desarrollados comprometan el $0.7 \%$ de su PGB en ayuda al mundo en desarrollo para el año 2015. Esta meta ya fue establecida en los años setenta, pero solo algunos países nórdicos han cumplido. Sin embargo, la magnitud de los problemas humanitarios y sus repercusiones en el propio mundo desarrollado si ellas no son abordadas a tiempo (por ejemplo, el problema de la inmigración ilegal, o la transmisión de enfermedades hacia las sociedades ricas) crean una necesidad que antes no existía, y que impulsa iniciativas novedosas, como por ejemplo el plan Blair para África, o las propuestas de Jeffrey Sachs para reducir la pobreza mundial en los próximos veinte años ${ }^{4}$.

Otra de las propuestas innovadoras del informe Annan es la creación de un Consejo de Derechos Humanos, que reemplazaría a la actual Comisión con sede en Ginebra, y que tendría una jerarquía similar al actual Consejo de Seguridad. En palabras del Secretario General, la idea es poner "a los derechos humanos a la par con los temas de desarrollo y los de seguridad"'. Hay un cierto consenso en que la actual Comisión ha perdido relevancia y legitimidad, en parte porque los mayores violadores de estos derechos se turnan en su membresía, impidiendo así que la Comisión los fiscalice y condene (Sudán, uno de los lugares donde hay mayores violaciones a los derechos humanos, es hoy miembro de la Comisión). Este tema seguramente generará controversia, pues hay muchos que no quieren relevar los derechos humanos dentro de las preocupaciones del organismo mundial, pero constituye un paso en la dirección de 2004.

5 "U.N Report Urges Big Changes", The New York Times, 1 de diciembre de 2004.

6 Fareed Zakaria, "Writing Prose for a New Term”, Newsweek, 15 de noviem- 
adecuada, si lo que se busca es mejorar la supervisión internacional en países donde no hay avances en la materia.

Se ha dicho muchas veces que si las Naciones Unidas no existieran, habría que crearla, pues se requiere de un foro mundial donde los países puedan debatir y buscar soluciones colectivas a problemas que afectan la paz, seguridad y desarrollo a nivel internacional. Las potencias fundadoras del organismo, especialmente Estados Unidos bajo el gobierno del presidente Franklin D. Roosevelt, concibieron a esta organización como el lugar donde los entonces aliados victoriosos de la II Guerra, debían enfrentar las nuevas amenazas a la seguridad internacional.

La descolonización de los años '50 y '60, trajo, por otra parte, una diversidad de temas e intereses que no formaban parte de la agenda original, y que ha llevado a una sobrecarga de tareas que por falta de recursos, voluntad política o inercias burocráticas, la organización no siempre cumple a cabalidad. Sin embargo, los grandes desafíos mundiales del siglo XXI (la pobreza, las epidemias, el terrorismo, los conflictos étnicos, la proliferación de armas de destrucción masiva, los desastres naturales, las crisis medioambientales, etc.), hacen hoy ineludible abordar de manera colectiva estos desafíos que traspasan las fronteras, y las capacidades de los Estados para resolverlas autónomamente.

Considerando la gravitación y poderío mundial de Estados Unidos, así como la contribución financiera que hace a la ONU (aproximadamente un $25 \%$ del presupuesto total), existen importantes interrogantes respecto de la política que seguirá la Casa Blanca en la segunda administración Bush, en relación con este organismo mundial. Si bien los neoconservadores que han dominado la política exterior son críticos acérrimos de la organización, y prefieren las acciones unilaterales o coaliciones "ad-hoc" (coalition of the willing) para resolver problemas donde Estados Unidos tiene intereses involucrados, las dificultades experimentadas en Irak y Afganistán, las tensiones con los socios de la OTAN, las aprensiones de la opinión pública doméstica, y las limitaciones políticas, de recursos e infraestructura para enfrentar otros desafíos internacionales que pudiesen surgir (lo que Paul Kennedy ha llamado "la sobre-extensión imperial"), generan un margen para una colaboración que no existió en el primer mandato. Como ha señalado el analista internacional Fareed Zakaria, más allá de la 
retórica, el gobierno de Bush en su segundo mandato ya ha debido recurrir a la cooperación internacional para abordar temas complejos como el terrorismo, la proliferación nuclear en Corea del Norte e Irán, para estabilizar Irak, impedir mayores tensiones en el estrecho de Taiwán, o impulsar un nuevo proceso de diálogo en el Medio Oriente ${ }^{6}$.

La colaboración de las grandes, y de las nuevas potencias, será indispensable para que la mayor parte de las reformas presentadas por el Secretario General tengan posibilidad de ser aprobadas en la próxima cumbre de jefes de estado de septiembre en Nueva York. Este conjunto de reformas son el resultado de un proceso de reflexión de largo plazo, donde personalidades ligadas al ámbito multilateral de distintas partes del mundo contribuyeron en la preparación de un documento que, más allá de las diferencias legítimas, busca fortalecer un sistema internacional a través de una nueva institucionalidad global que esté en sintonía con el mundo de hoy.

Tanto la legitimidad de las Naciones Unidas como la capacidad de acción colectiva en el futuro, dependerán de las decisiones que ahora se adopten para abordar los principales desafíos globales, $y$, en tal sentido, la propuesta del Secretario General constituye un paso útil y necesario, que deberá traducirse en consensos y acciones concretas en los próximos años, si es que se quiere actuar oportunamente frente a los principales dramas de nuestro tiempo.

bre de 2004. También ver sobre el mismo tema: "Bush and the World-Take 2", Foreign Affairs, Enero-Febrero, 2005. 